\title{
Target the message: A qualitative study exploring knowledge and cultural attitudes to sunlight and vitamin D in Greater Manchester, UK.
}

DOI:

10.1111/bjd.14800

\section{Document Version}

Accepted author manuscript

Link to publication record in Manchester Research Explorer

Citation for published version (APA):

Webb, A., Aseem, S., Kift, R., Rhodes, L., \& Farrar, M. (2016). Target the message: A qualitative study exploring knowledge and cultural attitudes to sunlight and vitamin D in Greater Manchester, UK. British Journal of Dermatology, 175(6), 1401-1403. https://doi.org/10.1111/bjd.14800

\section{Published in:}

British Journal of Dermatology

\section{Citing this paper}

Please note that where the full-text provided on Manchester Research Explorer is the Author Accepted Manuscript or Proof version this may differ from the final Published version. If citing, it is advised that you check and use the publisher's definitive version.

\section{General rights}

Copyright and moral rights for the publications made accessible in the Research Explorer are retained by the authors and/or other copyright owners and it is a condition of accessing publications that users recognise and abide by the legal requirements associated with these rights.

\section{Takedown policy}

If you believe that this document breaches copyright please refer to the University of Manchester's Takedown Procedures [http://man.ac.uk/04Y6Bo] or contact uml.scholarlycommunications@manchester.ac.uk providing relevant details, so we can investigate your claim.

\section{OPEN ACCESS}


Target the message: A qualitative study exploring knowledge and cultural attitudes to sunlight and vitamin D in Greater Manchester, UK.

\author{
A.R. Webb, ${ }^{1}$ S. Aseem, ${ }^{2}$ R.C.Kift, ${ }^{1}$ L.E. Rhodes $^{3}$ and M.D. Farrar ${ }^{3}$ \\ ${ }^{1}$ School of Earth, Atmospheric and Environmental Sciences, University of Manchester, \\ Manchester, U.K. \\ ${ }^{2}$ Centre for Primary Care Research, Institute of Population Health, University of Manchester, \\ Manchester, U.K. \\ ${ }^{3}$ Photobiology Unit, Centre for Dermatology, Institute of Inflammation and Repair, \\ University of Manchester, Manchester Academic Health Science Centre, Salford Royal \\ NHS Foundation Trust, Manchester, U.K.
}

Corresponding author: Ann R. Webb, SEAES, University of Manchester, Simon Building, Oxford Road, Manchester, M13 9PL, UK; Tel: 0161306 3917; E-mail: ann.webb@manchester.ac.uk

Word count: 997

Table count: 2

Funding sources: This study was funded by the U.K. Department of Health Policy Research Programme 024/0050.

Conflicts of interest: None declared 
Vitamin D is vital for musculoskeletal health and has been associated with protection against several internal cancers and auto-immune diseases. ${ }^{1,2}$ Skin synthesis following exposure to ultraviolet radiation (UVR) in sunlight is the major source of the vitamin, with diet providing only small amounts. ${ }^{3}$ Skin synthesis requires sunlight exposure containing sufficient UVB to initiate vitamin D synthesis, which precludes the winter months at midhigh latitudes, including the UK., Without continuous supplementation, maintaining vitamin D sufficiency, defined as circulating 25 -hydroxyvitamin D ( $25 \mathrm{OHD)} \geq 50 \mathrm{nmol} / \mathrm{L}$ (20 $\mathrm{ng} / \mathrm{ml}){ }^{2}$ is most efficiently achieved through casual sunlight exposure to unprotected skin. This contrasts with public health messages from the past 20 years advocating sun protection to reduce skin cancer risk, and to some cultural practices, exacerbated in those with naturally pigmented skin as melanin absorbs a proportion of the UVR. ${ }^{5,6}$

Studies in Greater Manchester, UK $\left(53.5^{0} \mathrm{~N}\right)^{5,7-9}$ involving white Caucasian and South Asian adults, showed sunlight exposure to be the primary means of acquiring vitamin $\mathrm{D}$ with diet a low source. A seasonal 25OHD cycle was observed in both groups, with lower amplitude in South Asian adults, of whom $93 \%$ had levels $<50 \mathrm{nmol} / \mathrm{L}$ throughout the year. ${ }^{9}$ Vitamin D guidance states "most people should be able to make enough from short, casual exposure like you might get just by going about your daily life" ${ }^{10}$ Thus we undertook a qualitative focus group study involving healthy white Caucasian and South Asian volunteers to explore knowledge and attitudes towards vitamin $D$ and sunlight exposure/protection behaviour. This methodology can effectively explore views and beliefs to understand/explain factors influencing individuals' attitudes and behaviours. ${ }^{11}$ Casual exposure was quantified as $\sim 15$ minutes to face, arms and legs, most days of the week during summer for white Caucasians, ${ }^{7}$ and 30-40 minutes for South Asians. ${ }^{6}$ The University of Manchester Research Ethics Committee granted ethical approval (Ref. 14133). Study 
documentation was made available in English and Urdu and all volunteers provided written informed consent.

Three focus groups were held from May-July 2014, defined by ethnicity and primary language (Table 1), conducted by a multilingual researcher experienced in focus group facilitation and supported by an English-speaking vitamin D expert. All volunteers were recruited from the Longsight area of Greater Manchester, avoiding confounding by socioeconomic status. A brief introduction was followed by open-ended questions, including general questions about sunlight and vitamin $D$ and more specific queries about personal sun exposure. There was ample interaction between group members and discussion was encouraged to continue until no new information was forthcoming. Audio recordings were translated where required, and transcribed into Microsoft Word. Transcripts were coded using MAXQDA11 (qualitative data analysis software) then exported to matrices for analysis by systematic text condensation.

For South Asian adults in Longsight, living in a strongly traditional community, primary language did not seem to indicate degree of cultural assimilation, although no volunteers had fully-adopted a western lifestyle (indicated by dress, language and cultural references). All but one of the South Asian volunteers were female who usually control the family diet and may influence health behaviour of family members. Most were restricted in dress by cultural traditions with results reflecting the cultural contrast between this group and white Caucasian participants (Table 2).

Level of awareness of vitamin D and its relationship to sunlight exposure was similar in the two South Asian groups but contrasted with that of white Caucasians. South Asians were much more knowledgeable, with the majority aware that vitamin D was important for bone health and could be obtained from sunlight exposure. White Caucasians had a substantial 
lack of knowledge with most unaware of vitamin D sources or its association with sunlight exposure. The greater knowledge of South Asians appeared to be primarily due to experience with symptoms of poor bone health, either directly or through a family member/community acquaintance, resulting in a GP visit and vitamin D blood test. Despite this greater knowledge, use of vitamin D supplements by the wider South Asian population in Greater Manchester is extremely low and levels of sunlight exposure less than those of white Caucasian adults in the same location. ${ }^{9}$ However, for South Asian participants taking supplements, this was their preferred method of vitamin D acquisition, while white Caucasians were generally averse to regular supplement taking. Thus, for South Asians, communication of advice may be inadequate rather than there being an unwillingness to take supplements.

National guidance to practise brief sunlight exposure for vitamin D acquisition was well received by white Caucasians, but was associated more with enjoyment of spending time outdoors in sunlight than with vitamin D. In contrast, some South Asians practised sunlight exposure specifically for vitamin D acquisition. There was, however, misunderstanding regarding the need for direct sunlight exposure to unprotected skin, with several participants incorrectly believing that exposure indoors through window glass was sufficient. Thus more explicit guidance is indicated; in addition to advice on amounts of sunlight exposure there needs to be education about how vitamin $D$ is acquired. White Caucasian participants were confused by mixed messages regarding sunlight exposure (risk/benefit) and frequently used sunscreen as they correctly associated sunburn and excessive sunlight exposure with risk of skin cancer. Furthermore, poor knowledge of dietary vitamin D sources meant many participants regarded a 'balanced diet' as being adequate. 
Few qualitative studies have explored sunlight exposure and vitamin D in healthy adults. Studies from Australia and the UK report lack of vitamin D knowledge and confusion surrounding contradictory sunlight exposure messages. ${ }^{12-14}$ Clearly risk/benefit and nutritional messages require better communication ${ }^{15}$. Our three focus groups felt that better information provided in a variety of formats would help raise awareness and let individuals make appropriate choices of their preferred source of vitamin D. Public health messages and education campaigns should include culturally appropriate advice to better target the needs of different population sectors.

\section{Acknowledgements}

This was independent research commissioned and funded by the Department of Health Policy Research Programme (Ref. 024/0050). Views expressed are the authors, not necessarily those of the Department of Health. We thank Caroline Lalley for transcription assistance. 


\section{References}

1. Holick MF. Vitamin D: importance in the prevention of cancers, type 1 diabetes, heart disease, and osteoporosis. Am J Clin Nutr 2004; 79:362-71.

2. Institute of Medicine. Dietary Reference Intakes for Calcium and Vitamin D. Washington, DC: The National Academies Press, 2011.

3.Webb AR, Engelsen O. Calculated ultraviolet exposure levels for a healthy vitamin D status. Photochem Photobiol 2006; 82:1697-703.

4. Kazantzidis A, Smedley ARD, Kift RC et al. Modeling approach to determine how much UV radiation is available across the UK and Ireland for health risk and benefit studies.

Photochem Photobiol Sci 2015; 14:1073-81.

5. Farrar MD, Kift R, Felton SJ et al. Recommended summer sunlight exposure amounts fail to produce sufficient vitamin D status in UK adults of South Asian origin. Am J Clin Nutr $2011 ; 94: 1219-24$.

6. Farrar MD, Webb AR, Kift Ret al. Efficacy of a dose range of simulated sunlight exposures in raising vitamin D status in South Asian adults: implications for targeted guidance on sun exposure. Am J Clin Nutr 2013; 97:1210-6.

7. Rhodes LE, Webb AR, Fraser HI et al. Recommended summer sunlight exposure levels can produce sufficient $\left(\geq 20 \mathrm{ng} \mathrm{ml}^{-1}\right.$ ) but not the proposed optimal $\left(\geq 32 \mathrm{ng} \mathrm{ml}^{-1}\right) 25(\mathrm{OH}) \mathrm{D}$ levels at UK latitudes. J Invest Dermatol 2010; 130:1411-8.

8. Webb AR, Kift R, Durkin MT et al. The role of sunlight exposure in determining the vitamin D status of the UK white Caucasian adult population. Br J Dermatol 2010; 163:1050-5. 9. Kift R, Berry JL, Vail A et al. Lifestyle factors including less cutaneous sun exposure contribute to starkly lower vitamin D status in UK South Asians compared to the white Caucasian population. Br J Dermatol 2013; 169:1272-8. 
10. Cancer Research UK. http://www.cancerresearchuk.org/about-cancer/causes-ofcancer/sun-uv-and-cancer/vitamin-d [accessed on 31 March 2016].

11. Hennink M, Diamond I. Using Focus Groups in Social Research, in Memon AA and Bull R (eds.) Handbook of the Psychology of Interviewing 1999. Wiley-Blackwell: New Jersey.

12. Bonevski B, Bryant J, Lambert $S$ et al. The $A B C$ of vitamin $D$ : a qualitative study of the knowledge and attitudes regarding vitamin D deficiency amongst selected population groups. Nutrients 2013; 5:915-27.

13. Vu LH, van der Pols JC, Whiteman DC et al. Knowledge and attitudes about vitamin D and impact on sun protection practices among urban office workers in Brisbane, Australia. Cancer Epidemiol Biomarkers Prev 2010; 19:1784-9.

14. Kotta S, Gadhvi D, Jakeways N et al. "Test me and treat me" - attitudes to vitamin D deficiency and supplementation: a qualitative study. BMJ Open 2015; 5:e007401. 15. NICE (National Institute for Health Care and Excellence). Sunlight Exposure: Risks and Benefits. NICE Guideline 2016: www.nice.org.uk/guidance/ng34 (accessed 11/4/2016) 
Table 1 Details of Focus Groups and volunteers

\begin{tabular}{lccc}
\hline & Group A ( $\mathrm{n}=10)$ & Group B ( $\mathrm{n}=10)$ & Group C $(\mathrm{n}=6)$ \\
\hline Ethnicity & South Asian & South Asian & White Caucasian \\
& (Pakistani) & (Pakistani) & (white British) \\
Primary language & $0 / 10$ & English & English \\
No. male / female & $24-65$ & $1 / 9$ & $2 / 4$ \\
Age range (years) & 1 & $21-55$ & $24-60$ \\
Focus group duration (hours) & & 1.5 & 1 \\
\hline
\end{tabular}


Table 2 Illustrative responses from Focus Group participants on the main topics of discussion.

\begin{tabular}{llll}
\hline Topic & South Asian & $\begin{array}{l}\text { White } \\
\text { Caucasian }\end{array}$ & Comments/quotes \\
& $($ Grp A \& B) & (Grp C) &
\end{tabular}

Knowledge
Aware that
sunlight is a
source of vitamin
D

Aware of how

No

$\begin{array}{ll}\text { Common } & \text { Not well } \\ \text { knowledge } & \text { known }\end{array}$

much sun

exposure is

required

Sun exposure
advised by
physician
Understand need
to expose

Yes

Some

$\mathrm{n} / \mathrm{a}$

confusion

unprotected skin

No

No
Understand risks

of sun exposure

No

Yes

Behaviour

Expose skin to sun often

Yes but Yes limited areas
"My GP told me to sit in the sun, so I do it." Group A

"I don't have a private garden; it is over looked, so whenever I get time I usually sit in my conservatory near the window to get sunlight." Group A

"Some of things that you're told not to do.... you're not supposed to go out in the sunshine unless you've got sunscreen." Group $C$

"I know that you can make it [vitamin D] from the sun but I tend to stay out of the sun because I'm pasty and I'm pale and I burn really easily." Group C
"I also like sitting out in the sun at home, usually for 15 or 20 minutes 
[daily] and sometimes more every summer." Group B

Wear sunscreen No Yes frequently

Expose more than hands/face/neck

Limited (females)

Yes (both sexes)
"I've probably got some kind of skin cream on most of the time with some kind of protection in.... mostly I use sunscreen as well, so I think a lot of women would be the same, especially women over 35." Group $C$

"I think the clothing styles of men in our Asian culture are different as compared to females.... we usually wear T-shirts and shorts in summer. There won't be any issues with the male members as they are allowed to wear all sorts of clothing but there will be limits for females." Male, Group B

"My daughters are aware of it and they usually sit outside in the back garden turning up their trousers till knees and sometimes they wear sleeveless shirts so that they could expose their skin to sunlight. This happens when the male members of the family are not there and are at work and all the females are at home. We have cultural and religious obligations and cannot allow them to cross those limits." Group A

Been prescribed Yes

No

Several South Asian participants were happy to take a prescription supplement.

No

National guidance is $10 \mu \mathrm{g}$ vitamin D/day orally for South Asians, but no pro-active effort to follow his advice

"I would love to take supplement tablets as it's the easiest way." Group A

“No, no.... not any more tablets as I 
take about ten already." Group C

Focus Group

suggestions for

increasing awareness
GPs to better advise patients on vitamin D sources including casual sunlight exposure.

Posters in recreational facilities, community centres, places of worship.

Specific targeting of South Asian women regarding greater skin exposure.

Discussion groups/workshops for general public, schools. 